DOI: http://dx.doi.org/10.33846/hn30405

http://heanoti.com/index.php/hn

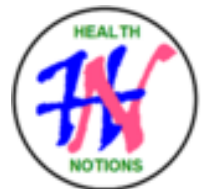

RESEARCH ARTICLE

URL of this article: http://heanoti.com/index.php/hn/article/view/hn30405

\title{
Management of Geographic Tongue, Fissure Tongue, and Oral Candidiasis on Dorsum of an Elderly Smoking Patient's Tongue
}

\author{
Sri Hernawati ${ }^{1(\mathrm{CA})}$ \\ ${ }^{1(\mathrm{CA})}$ Oral Medicine Department, Dentistry Faculty, Jember University; srihernawati.drg5@ yahoo.com \\ (Corresponding Author)
}

\begin{abstract}
Background: A geographic tongue is an inflammatory lesion of the tongue accompanied with atrophy formation of papilla or depapilation of the filiform papillae. The geographic tongue usually appears together with the appearance of the fissure tongue, a midline, multiple, fissure on the surface of the tongue that expands from front to back and has various patterns. Predisposing factors of geographic tongue and fissure tongue are nutritional deficiencies and stress. Oral candidiasis is one of the fungal infections that affect the oral mucosa caused by the fungus Candida albicans. Predisposing factors of oral candidiasis e.g. stress, and smoking habits. Case: 64-year-old male patient with a clinical appearance on the dorsum of the tongue in a bracelet-like form with depapilation, vertical fissure $3 \mathrm{~mm}$ deep and thick white plaque which could be scraped and felt painful. Diagnosis: geographic tongue, fissure tongue and oral candidiasis. Therapy: aloe vera in oral solution as antiinflammatory and analgesic, Nystatin oral suspension functions as a topical antifungal medicine, multivitamin Becomzet (Vitamin B complex, A, C, E, and Zinc) as a multivitamin. Conclusion: after therapy using aloe vera solution, nystantin becomzet controls both patients had undergone a healing process in both the case of geographic tongue, fissure tongue and oral candidiasis.
\end{abstract}

Keywords: Geographic tongue, Candidasis

\section{INTRODUCTION}

\section{Background}

Geographic tongue or benign migratory glossitis or erythema migraines is an inflammatory lesion on the tongue that is benign and has no tendency to change into malignancy. This disorder occurs on the tongue, especially on the dorsum or on the lateral part of the tongue. Lesions on the geographic tongue are asymptomatic because there is atrophy of the papilla or depapillation of the filiform papilla which is capable of changing sensation ${ }^{(1)}$. The geographic tongue lesion appears clinically as a depapillation area, yellow or white, or gray color, and appears elevated at its edges with irregular formation ${ }^{(2)}$. The geographic tongue usually appears together with the appearance of fissure tongue ${ }^{(3)}$. The fissure tongue is a state of variation from the normal tongue anatomy which consists of a midline or multiple fissures over the surface of the tongue that expands from front to back and has various patterns ${ }^{(4)}$. Most fissure tongue sufferers experience no symptoms, but symptoms e.g. pain when eating hot or sour food may occur if the fissure gap is deep. The gap may act as a place to accumulate food particles and bacteria that may cause inflammation in the tongue ${ }^{(5)}$.

Oral Candidiasis is one of the fungal infections that affects the oral mucosa. This lesion is caused by the fungus of Candida albicans. Candida albicans is a normal flora of the oral cavity, digestive tract and vagina, this fungus can turn into a pathogen if changes occur in the host. Changes that occur in these hosts can be both local and systemic. Candida albicans is one component of oral microflora and about 30-50\% of people are carriers for this organism. There are five types of candida species found in oral cavities including Candida albicans, Candida tropicalis, Candida krusei, Candida parapsilosis and Candida guilliermondi ${ }^{(6)}$. The most 
common forms of candidiasis lesions found in the oral cavity are pseudomembranes and erythematosus. Pseudomembranes have clinical signs in the form of white patches or plaque lesions found on the tongue, palate, and buccal, broken off if scraped leaving a red mucous surface and can be accompanied by mild bleeding. Erythematosus is also known as evening antibiotic mouth because it is associated with long-term broadspectrum antibiotic use. Candidiasis erythematosus is clinically characterized by a red area usually on the dorsum of the tongue and palate and rarely occurs in the buccal mucosa. Candidiasis erythematosus is a form of candidiasis accompanied by constant pain or burning sensation ${ }^{(7)}$.

\section{Cases}

A 64-year-old man, weighing $65 \mathrm{~kg}$ and height of $170 \mathrm{~cm}$ came to the Oral Medicine Clinic, Dental and Oral Hospital (RSGM) of the University of Jember on July 19, 2018 to have an examination of his painful and sore tongue especially when eating hot and sour food. In addition he felt his tongue thick, turned white, and found gaps on it. He had tried to treat it using mouthwash solution. The patient had a bad habit of smoking 12 cigarettes a day.

On the extra-oral clinical examination of the oral cavity no abnormalities were found. However, on the intra-patient examination of partial edentulous ridge, on the dorsum of the tongue there were found a braceletshaped formation with depapillation was found, a vertical fissure $3 \mathrm{~mm}$ deep, and thick white plaque that could be scraped and felt sore (figure 1). Temporary diagnosis was geographic tongue, fissure tongue, and suspect oral candidiasis in the posterior part of the tongue.

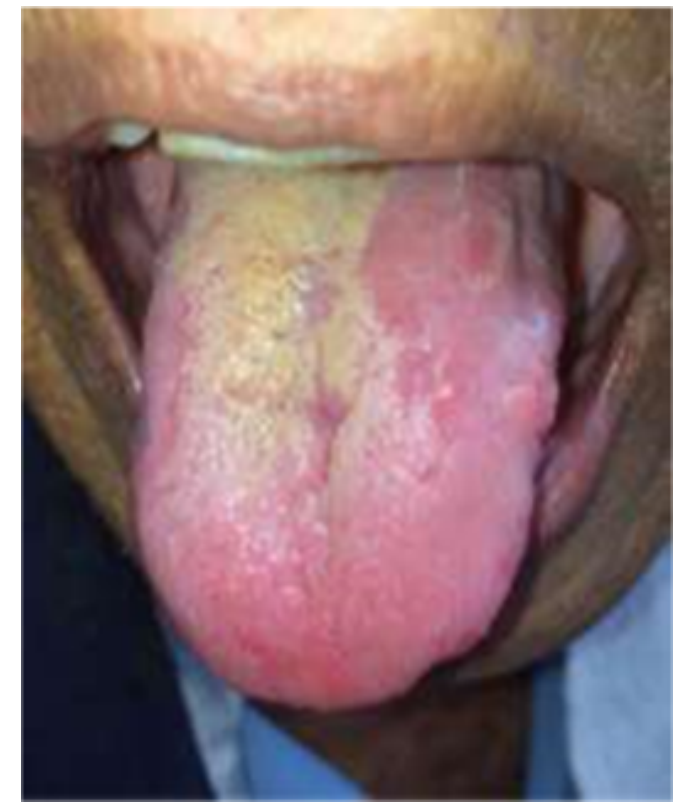

Figure 1. Initial photo before treatment

\section{Case Management}

The management of the geographic tongue and fissure tongue began with cleaning and drying the lesion with sterile pellet cotton, then the lesion was smeared with antiseptic povidone iodine. Then the lesion was smeared with aloevera in oral solution using sterile cotton pellets and stayed for 5 minutes.

The management of oral candidiasis suspect began with oral swab by cleaning the tongue with a sterile tampon. Subsequently, it was scraped using a cement spatula for oral smear. Then asepsis was performed using povidone iodine. The yellow part of the tongue was dripped with nystatin and applied evenly. The patient was instructed not to eat or drink for 20 to 30 minutes. He was also provided multivitamin of B complex and zinc once a day. The patient was instructed to eliminate bad habits e.g. smoking, and suggested to eat nutritious foods (high protein), to have adequate rest, and to go control one week, moreover he should take the medication as recommended, and maintain oral hygiene. The patient came back after six days of treatment and said that he did not feel pain on his tongue anymore, however he still felt his tongue was slightly thick. The medicine provided i.e. aloe Vera in oral solution and oral suspension nystatin was still half a bottle remained, and the 
multivitamin remained four tablets. The intra-oral examination showed a $2 \mathrm{~mm}$ vertical fissure and there was thick white plaque scraped (Figure 2).

Based on the results of control I, the treatment was still conducted as recommended, maintaining cleanliness of the oral cavity, eliminating smoking habits, eating nutritious foods (high in protein), having adequate rest. The patient came back after five days of control I because the patient still felt a little thick on the tongue. The results of the anamnesis, the patient did not feel painful and sore anymore as well as the thickness on his tongue. The medicine provided i.e. aloevera in oral solution and oral nystatin suspension had run out, multivitamins were also used up. The extraoral and intraoral examination showed no abnormalities (Figure 3). Based on the results of the control II, the patient was provided multivitual medication and treatment according to recommendations, maintaining cleanliness of the oral cavity, eliminating smoking habit, eating nutritious foods (high in protein), adequate rest.

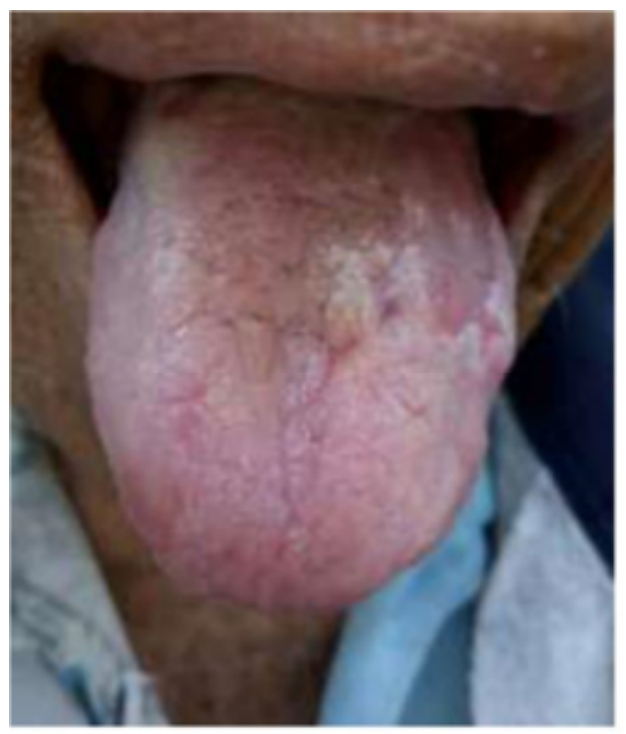

Photo before control I

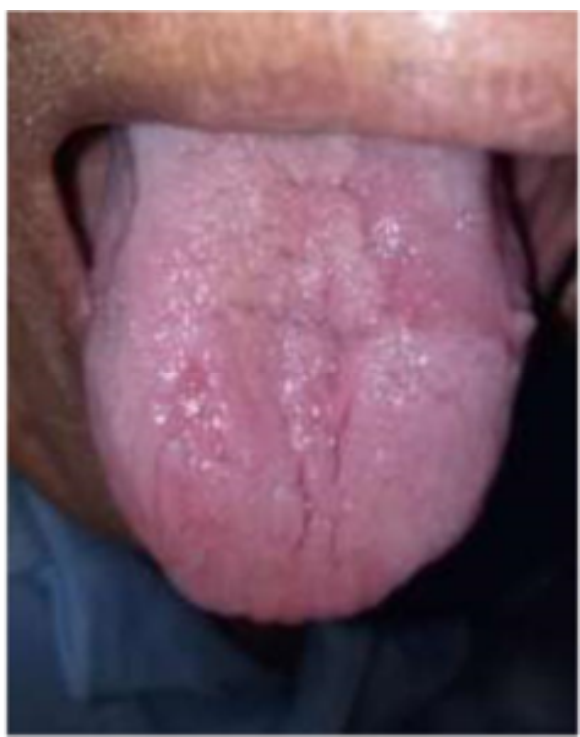

Photo after control I

Figure 2. The condition before and after control I

\section{Discussion}

Based on the case, the diagnosis might be made from the results of subjective examination in the form of anamnesis of the patient and clinical examination.

The results of the anamnesis demonstrate that the patient has a bad habit of smoking 12 cigarettes a day. The habits of smoking could emerge oral mucosal abnormalities. The past smoking habit carried out by elderly may affect the function of salivary flow causing xerostomia, this occurs because of the interaction between cigarette smoke and the flow of saliva leading to the reduction of saliva flow ${ }^{(8)}$.

The etiology of the geographic tongue is not yet known, although many studies have examined the geographic tongue, some researchers said that it derives from genetic or hereditary factors. Predisposing factors also support the occurrence of geographic tongue e.g. nutritional deficiencies and stress ${ }^{(9)}$. The fissure tongue that occurs in the patient is established by looking at the clinical description. The suspected fissure was due to inflammation of the tongue fissure. Inflammation can occur because the poor hygiene of the tongue which may be caused by debris and bacteria ${ }^{(6)}$.

Some researchers report that smoking can significantly increase the number of Candida from $30 \%$ to $70 \%$. The types of cigarettes smoked also contribute to the increasing number of candida colonies in the oral cavity. Types of cigarettes e.g. filter cigarettes have filter foam that prevent and minimize the levels of harmful substances i.e. nicotine, tar, and carbon monoxide to enter the body compared to clove cigarettes with no filter foam. Hemoglobin has a higher affinity for carbon monoxide compared to oxygen therefor when carbon monoxide presents, hemoglobin binds more to carbon monoxide. This causes oxygen cannot be channeled to all organs of the body causing the organs do not function properly due to lack of oxygen. The organs lacking oxygen may disturb the entire body system, including the immune system. Decreasing the immune system causes host cells to not able to kill pathogens e.g. candida allowing them to multiply beyond normal limits ${ }^{(10)}$. 
The most famous group of hydrolytic enzyme secretions of C. albicans is SAP. (Secreted Aspartyl Proteinase). Attachment to host cells and tissues is very important for C. albicans in initiating invasion, subsequently spread into host organisms. On the cell wall surface C. albicans provides receptors responsible for adhesion to epithelial and endothelial cells, serum proteins and extracellular matrix proteins. Adhesion and biofilm formation are currently a serious problem in medicine, because of frequent resistance to antifungal agents and increased pathogenicity among sub-populations of cells that form biofilms. During the formation of SAP secretion biofilms is higher. C. albicans forming biofilms are always associated with polysaccharide matrices containing mannose and glucose residues. Biofilm matrix production plays a very important role in medication resistance in C. albicans biofilm, but the development of resistance can be multifactorial. Changes in colonies that are originally white, oval and smooth can also turn into gray and rough colonies. Dull colored cells produce SAP1 and SAP3 are less virulent, while white cells produce SAP2 and are more virulent during systemic infections. ${ }^{(11)}$

Acute pseudomembranous candidiasis (thrush) is established by observing the clinical description of the lesions found on the patient's dorsum, and the results of mycological support carried out in the microbiology laboratory, Dentistry Faculty, Jember University showed the presence of +2 (Positive 2) and hypha +3 (Positive 3 ) spores. The etiology of the disease is the fungus Candida albicans. In this case the patient was 64 years old included in the elderly group. In the elderly group, their immune ability decreases according to increasing age including the speed of the immune response against infection. Old people who generally suffer from lack of macro and micro nutrition will have low system response and immune function. In old age the aging process begins, where the cell regeneration process decreases and cells in the salivary gland also possibly degenerate. This can lead to decreased salivary secretion, where the function of the cleansing agent in the oral cavity decreases. Saliva contains various components of the defense mechanism against infection, one of which is the content of Ig A, Ig G and Ig M, leukocytes, lactoferrin, etc. Immunoglobulin plays a role in the process of eliminating bacteria and fungi. Therefore, decreased quantity of saliva in the oral cavity may trigger the albican candida to become a pathogen ${ }^{(6)}$.

The plan for treatment and therapy is symptom therapy which aims to reduce pain using aloe Vera in oral solution by applying it to the geographic tongue and fissure tongue three times a day. Nystatin in oral suspense is applied to the yellow area to reduce the thickness on the tongue. The treatment applied to patients is the administration of the nystatin oral suspension. Nystatin is a polyene macrolide which is a first-line medicine in oral candidiasis in topical forms. Nystatin is available in the form of creams and oral suspensions. There are no medication interactions and significant side effects on the use of nystatic as anti-candidiasis. Polyene antifungi bind to elgosterol in fungi cell membranes resulting in disruption of the cell membrane structure which causes leakage of intracellular content that ends with cell death ${ }^{(12)}$. Supportive therapy uses multivitamins Becomzet tabs with instructions to take medication once a day after meals.

Supportive therapy Becomzet tabs contains Vitamin B complex, A, C, is conducted to support the healing process. The patient was instructed to use the medication as recommended, to maintain cleanliness of the oral cavity, to eat nutritious foods (high in protein), and to have adequate rest ${ }^{(13)}$.

\section{CONCLUSION}

It can be concluded that the patient has geographic tongue, fissure tongue and oral candidiasis. After the control II carried out, a healing process and therapy provided is aloevera in oral solution and nystastin in oral suspension as symptomative therapy and multivitamin Becomzet as supportive therapy.

\section{REFERENCES}

1. Musaad AH, Abuaffan AH, Khier E. Prevalence of Fissured and Geographic tongue Abmormalities among University Student in Khartoum State, Sudan. Enz Eng. 2015;5(1).

2. Shahzad M, Sattar A, Ali SMF. Geographic tongue: Case Report and Literature Review. Pakistan Oral \& Dental Journal. 2014;34(3).

3. Bajaj, Kapoor, Garg, Mohammed, Sabharwal, Vaidya. Geographic tongue in A 6 Years Old Child: A Case Report With Review Of Literature. Dental Journal of Advanced Studies. 2013;1(2).

4. Pindborg J.J. Atlas of Oral Mucous Disease. Jakarta: Binarupa Aksara; 2009.

5. Patil S, Kaswan S, Rahman F, Doni B. Prevalence of tongue lesions in the Indian population. J Clin Exp Dent. 2013;5(3):128-132.

6. Darma, Candra Adi and Leni Rokhma Dewi. Case report: Acute Pseudomembranous Candidiasis (trush) management on Dorsum and Fissure tongue on Ventral tongue. Jember: Proceeding The 4th Dentistry Scientific Meeting of Jember. 2017. 
7. Nur'aeny, Nanan, Hidayat W, Dewi TS, Herawati E, Wahyuni ES. 2017. Pro 1 oral candidiasis in oral medicine department RSHS Bandung 2010-2014 period. Majalah Kedokteran Gigi Indonesia. Erna;3(1).

8. Thomson WM, Lawrence HP, Broadbent JM, Poulton R. The impact of xerostomia on oral health-related quality of life among younger adults. Health Qual Life Outcomes. 2006;4:86.

9. Burket, Greenberg, Glick, Ship. Burket's Oral Medicine Elevent Edition Canada: BC Decker Inc.

10. Geiss O, Kotzias D. Tobacco, cigarettes and cigarette smoke: An overview. Institute for Health and Consumer Protection. 2007;40-53.

11. Lestari PE. The role of virulence fantors on Candida Albicans infection pathogenesis. Stomatognatic (J.K.G Unej). 2010;7(2).

12. Pharmacology and Therapy Department Medicine Faculty University of IndonesiaFK UI. Pharmacology and Therapy. Jakarta: FKUI; 2007.

13. Yanhendri, Satya WY. Various Forms of Topical and Dermatology Preparations (Berbagai Bentuk Sediaan Topikal dan Dermatologi).Padang: FK-UNAND; 2012. 